\title{
The readability of online patient resources for skin cancer treatment
}

Thomas Dobbs ${ }^{1}$, Giles Neal ${ }^{2}$, Hayley Hutchings ${ }^{1}$, lain Whitaker ${ }^{1}$ and Jim Milton ${ }^{1}$ 1 - Swansea University 2 - Oxford University Medical School

\section{Introduction}

- $\quad$ Skin cancer is the most common malignancy worldwide ${ }^{1}$

- $\quad 80 \%$ of Internet users have accessed health information online ${ }^{2}$

- 1 in 6 UK adults have reading level below that expected of 11 year old ${ }^{3}$

- $\quad$ Poor literacy levels lead to poor health literacy $=$ health inequality

- Recommended that all health literature written at or below the $6^{\text {th }}$ grade level $(11 \text { year old })^{4}$

\section{Methods}

- Google, Yahoo and Bing searched with the term 'skin cancer treatment'

- $\quad$ All location, account information and cookies disabled

- Top 20 from each site given reverse score from $20-1$

- $\quad$ Aggregate top 10 scores taken

- $\quad$ All text on top 10 sites downloaded

- $\quad$ Analysed with set of readability formulae

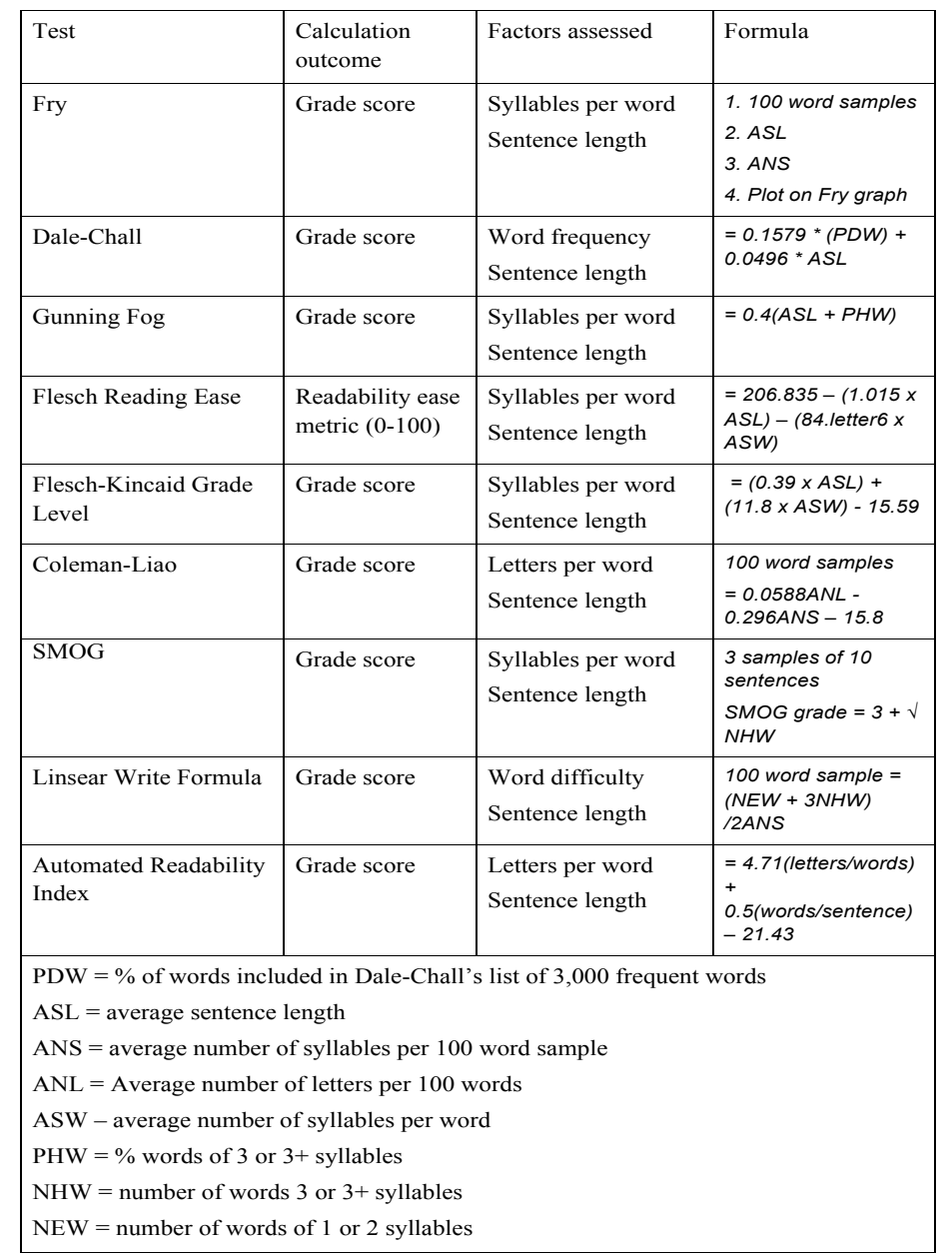

Figure 1: Readability formulae used to determine readability level of assessed websites
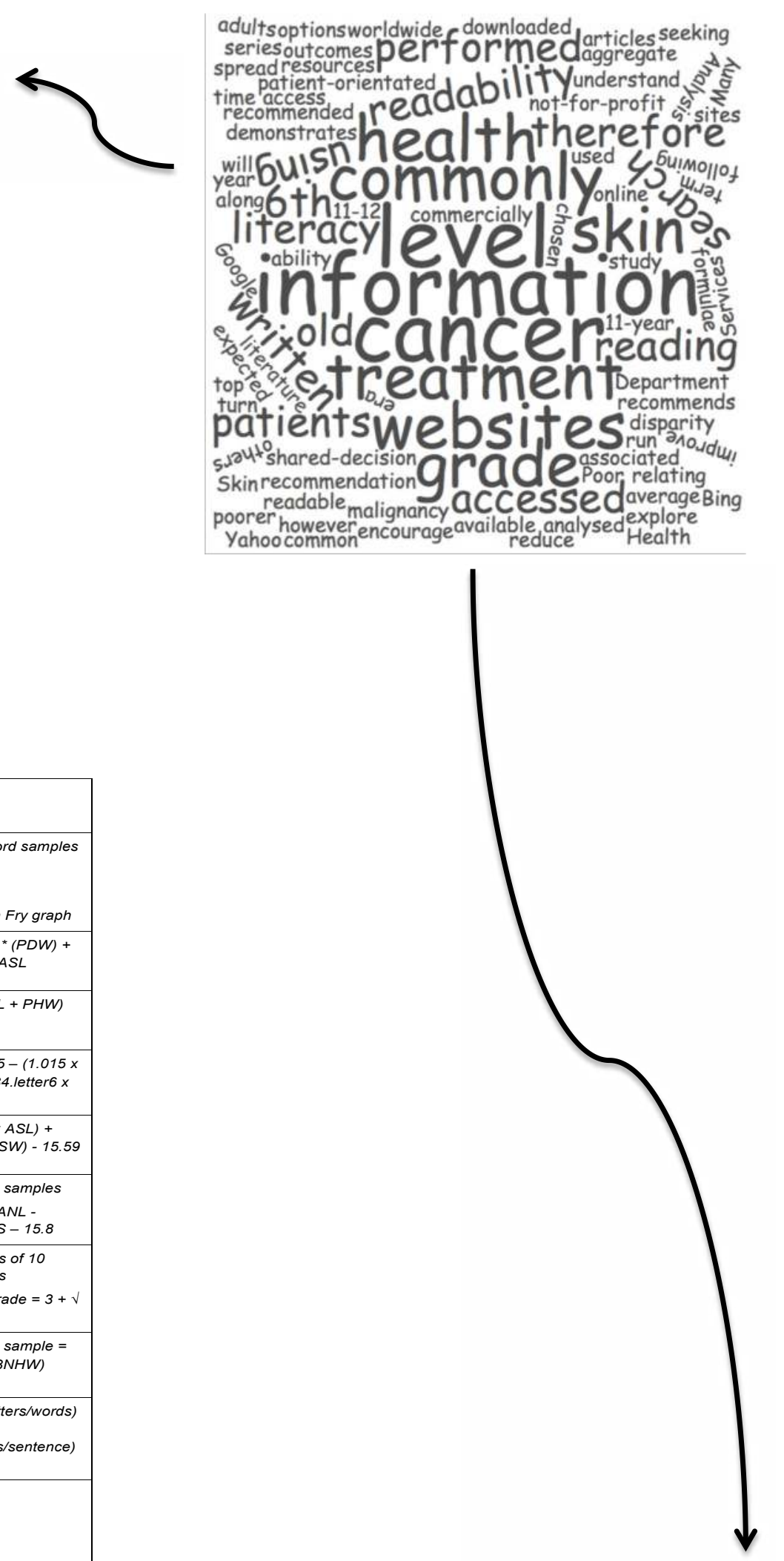

Results

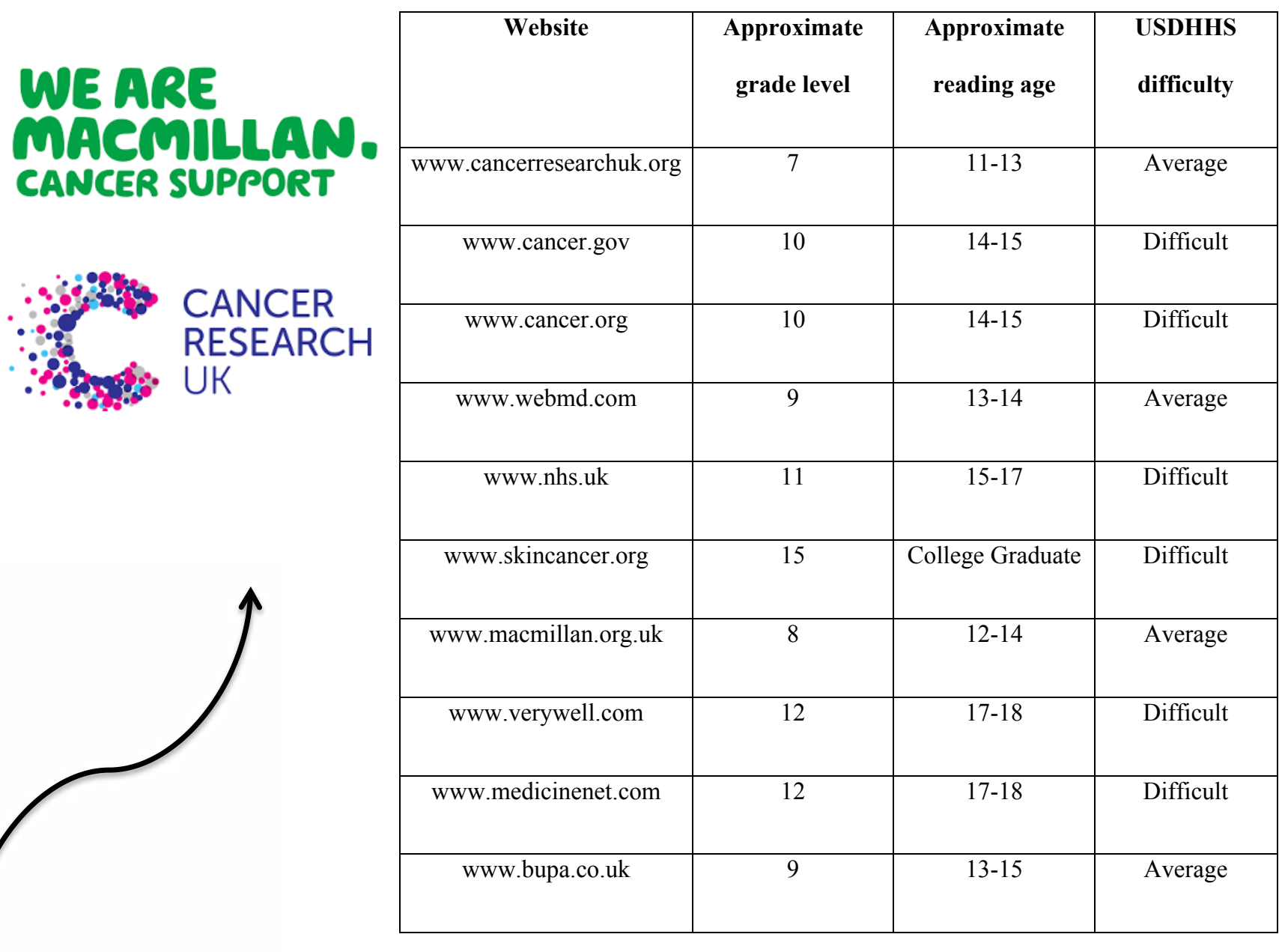

Figure 2:Top 10 websites using the search term 'skin cancer treatment. Approximate grade level, UK reading level and US Department of Health and Human Services classification.

- All websites above the recommended $6^{\text {th }}$ grade level

- No statistical difference between top and bottom 5

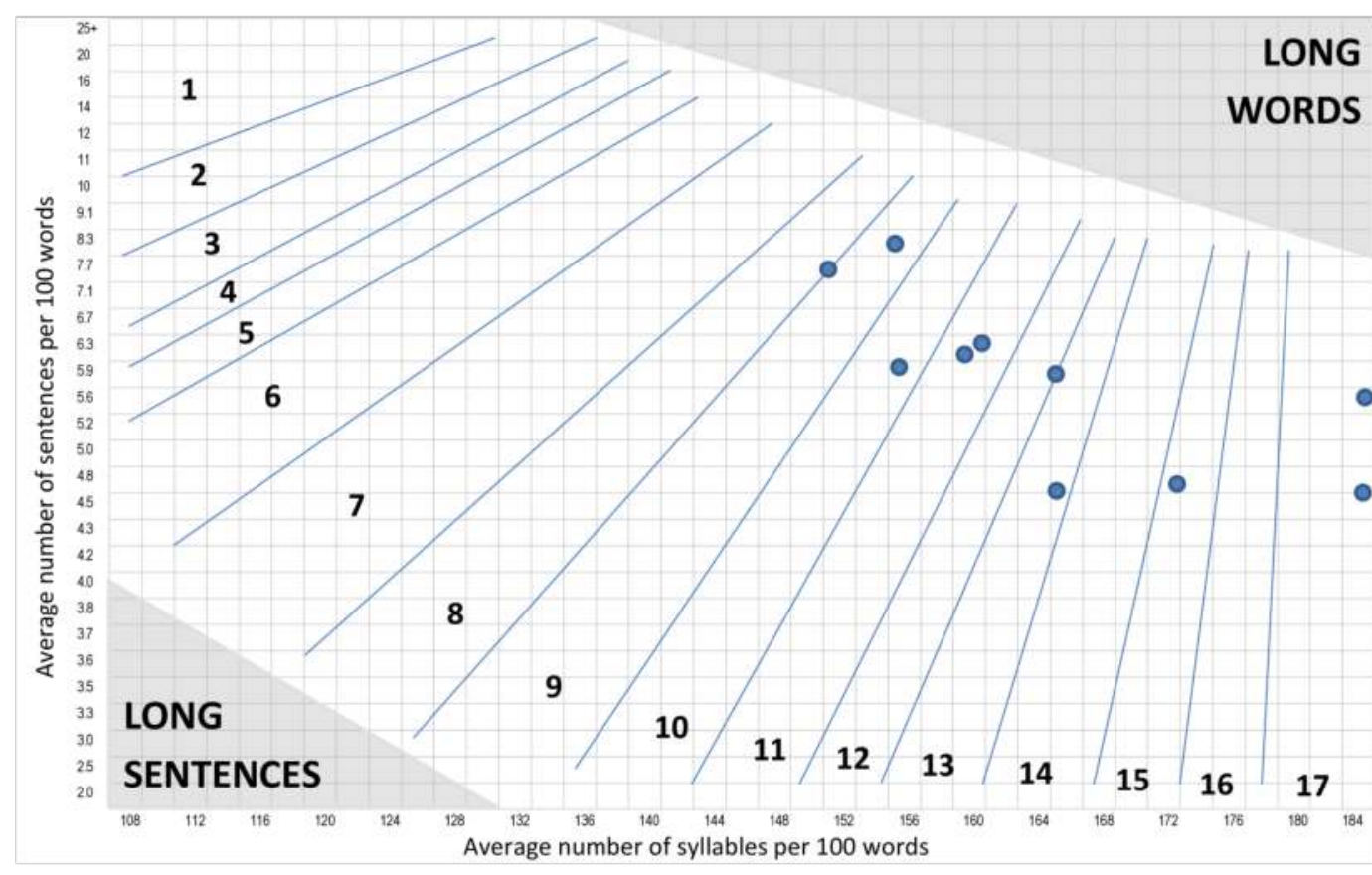

Figure 3: Fry Graph demonstrating US grade level of websites analysed. All are above the recommended US $6^{\text {th }}$ grade level.
- All resources assessed in this study written above the recommended level

- Two written at University level

- Medical terminology difficult to understand any many words polysyllabic

- Need glossary of terms 